\author{
Elizabeth M. McNally
}

\begin{abstract}
$\mathrm{t}$ is an honor and privilege to address you as president of the American Society for Clinical Investigation. For more than 100 years, this organization has represented the best of physician-scientists. Since it is now 2012, there is the possibility that this could be the last ASCI presidential address. But we will assume the Mayans miscalculated and that we should look to the future. With the ASCI moving into its second century, this year we decided it was time to solicit the opinion of its membership and essentially ask ASCI members, "How are we doing? What do we want from ASCI?" We surveyed ASCI members about key areas: membership, council service, fiscal policy, The Journal of Clinical Investigation, this meeting, and what membership expected from this organization.
\end{abstract}

\section{The age question}

Election to ASCI has an upper age limit of 45 , with the intent that the Society represents an "ascending career" physicianscientist. The Society has three main membership categories. Active membership is restricted to those under 51, and these members have voting privileges and may serve on Council. After age 51, one passes into Senior membership status. Senior membership is somewhat akin to AARP. Senior members are far from retired, but Senior members are no long eligible to vote nor may they serve on ASCI Council. Lastly, there are Emeritus members who are no longer active as physician-scientists and who are more than age 65 .

The ASCI currently has 413 Active members, 1,180 Senior members, and 1,471 Emeritus members. There are also 22 Honorary members and 3 Foreign Associate members. Last November, we surveyed all membership categories and

This article is adapted from a presentation at the 2012 ASCI/AAP Joint Meeting, April 28, 2012, in Chicago, Illinois, USA.

Address correspondence to: Elizabeth M. McNally, The University of Chicago, 5841 S. Maryland, MC6088, Chicago, Illinois 60637, USA. Phone: 773.702.2672; Fax: 773.702.2681; E-mail: emcnally@uchicago.edu.

Citation for this article: J Clin Invest. 2012; 122(11):4274-4279. doi:10.1172/JC66800. had a $64 \%$ response rate from Active members. When we asked about the age issue, approximately half of survey respondents favored increasing the age of election to ASCI. More than half favored extending the maximum age for Active status. Increasing the age at which one transitions to Senior status would considerably broaden ASCI Active membership, and it would most critically open the number of members eligible to serve on Council. Based on these responses, the Council has actively discussed a proposal to increase the age of Active membership and the age of Emeritus membership. We can expect that a ballot will be put forward soon to vote on the age issue.

It is fair to question why we should change the age of election to ASCI or any of these other categories. The answer is for the health of our organization. The ASCI was organized in 1909, the year after the Cubs last won the World Series. While the trajectory of my beloved Cubs has not changed, the time to become a physician-scientist has. Most relevant to this point, postgraduate medical education as well as postdoctoral research training has considerably lengthened. The age at which an MD gets his first NIH grant is 44, and the time an MD gets her first NIH grant is probably not lower (Figure 1). With the age to first grant dangerously eclipsing the maximum age of ASCI election, it does not require an advanced degree to calculate that it is time to extend the maximum age for ASCI election.

\section{Society finances and planning for the future}

In the survey, we also polled members about fiscal strategy. The ASCI has an endowment, and this endowment serves as the backing for our major fiduciary responsibility, publishing The Journal of Clinical Investigation. Since the ASCI endowment is invested in the stock market, like many of our institutional and personal holdings, the market decline during 2008 and 2009 negatively affected the ASCI endowment. The Society's finances are audited annually. When the auditors queried our fiscal strategy, we found little guidance in the
ASCI bylaws. In the survey, we asked ASCI members about deficit spending, planning for budget surplus, and managing reserves. These opinions provided guidance as we formulated a fiscal spending policy that the Council has now passed. This policy will be carefully reevaluated in 2 years, and we expect that this policy will steer the ASCI for the future and provide strong backing for the JCI.

\section{The Journal of Clinical Investigation}

The JCI remains the preeminent journal of molecular medicine, holding a respected place in publishing, in part because of its organization, as reflected in its impact factor. Of high-impact journals, it is unique because of its editorial board, composed of physician-scientists, that broadly spans many disciplines. From an operational view, the JCI stands alone, not part of a "journal bundle," and the JCI is self-published. The bundled journal strategy currently dominates publishing, and larger publishing houses have courted the JCI unsuccessfully. We are confident that the journal will be immensely successful in its new home at Duke University and the University of North Carolina under the stewardship of Howard Rockman. I draw your attention to the fact that the JCI was the original open access journal. Content of JCI research papers remains free to all. For those who may note or even lament the page charges for publishing in the JCI, these charges support the open access model. So by publishing in the JCI, your best work is available to all to read for free.

\section{The Joint Meeting and APSA inclusion}

In our survey, we queried ASCI membership about the value of this Joint Meeting. The membership strongly supported the meeting, especially the recent addition of American Physician Scientists Association (APSA). APSA has been increasingly folded into what is now a tri-organization structure of the Joint Meeting, with the recognition that these young physician-scientists are our future ASCI and AAP members. This year, for the first time, APSA repre- 


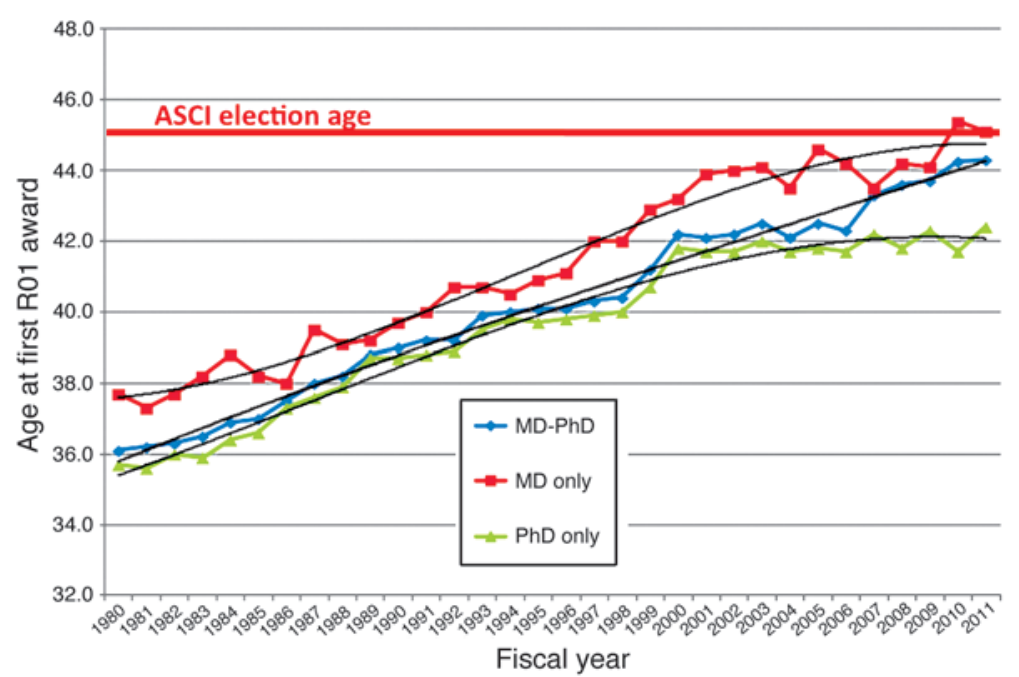

sentatives were full participants in planning the Joint Meeting, and I think it is safe to say that this Joint Meeting now fully integrates all three societies: ASCI, AAP, and APSA.

\section{ASCl's membership in advocacy organizations}

One issue that resonated loudly through the survey responses was membership's expectation of the importance of advocacy for ASCI. Specifically, more than $85 \%$ of membership agreed that advocacy with federal funding agencies was an important role for the ASCI. With the Washington mantra to reduce federal spending and its impact on our lifeline, the NIH budget, it is not surprising that advocacy is now front and center. The research community is not alone in suffering from the federal squeeze, and we need to position ourselves with our funders, the taxpayers, so that science remains a priority for our elected officials who appropriate the budget. I hope to convince you that advocacy is not only the mission of the ASCI, but it should be a mission for each and every one of us.

When I joined the ASCI Council five years ago, I took on a responsibility for our advocacy missions. The Society participates in multiple advocacy organizations with the recognition that we are a comparatively small organization and that there is strength in numbers. We are one of the 26 members societies of FASEB, the Federation of American Societies for Experimental Biology, an organization that this year is celebrating its 100th anniversary. FASEB, through this conglomeration, represents 100,000 scientists and is the largest organization of biological scientists. FASEB's missions are many, but they center on the dissemination of scientific information through publications, educational programs, and meetings.

FASEB's Office of Public Affairs is an active group that is an excellent source of information on federal policy related to research, including funding (1). Last spring, FASEB cohosted a conference on engaging basic researchers in translational science. Representatives from FASEB's member organizations, NIH leadership, Howard Hughes Medical Institute, Doris Duke Charitable Foundation, Burroughs Wellcome Fund, and others worked together to outline strategies to improve translational research focus on multiple aspects from training to technology transfer and to examine approaches used throughout academia and those newer approaches now beginning at the NIH. FASEB's size and staffing allows it to be a ready source of information on research trends, including funding information. FASEB stays abreast of federal budget planning and taps into membership at critical points during the long process of determining the federal budget for research. FASEB regularly communicates with NIH, the White House Office of Science and Technology Policy, and congressional leadership. Because of FASEB's size and organization, its opinion matters.

The ASCI also advocates through its participation in the Coalition for Life Sciences, or CLS (2). CLS is a smaller and more focused organization devoted to congressional outreach, education, and advocacy. In the last several years, CLS has been nearly singular with its focus on identifying the benefits of and promoting federal

\section{Figure 1}

Average age of principal investigators with an MD, MD/PhD, or PhD at the time of first R01 equivalent award from $\mathrm{NIH}$, fiscal years 1980-2011. Reproduced from "Rock Talk," Sally Rockey. Posted February 3, 2012 (http://nexus. od.nih.gov/all/2012/02/03/our-commitment-tosupporting-the-next-generation/).

funding for research. CLS hosts a series of educational seminars throughout the year for the Congressional Biomedical Research Caucus. This caucus, established in 1989, is notable in that it is bipartisan, with 75 House members and 8 Senate members, and its leadership derives from both political parties. The Coalition for Life Sciences advises the caucus and hosts seminars throughout the year. Recent topics covered in these sessions included new therapies for melanoma, the biological basis of obesity, and strategies for cardiac repair. These sessions are attended by congressional members and staff, and they provide a unique opportunity for scientists to talk directly to Congress about advances in science. In a given calendar year, this may be one of the only opportunities for a member of Congress to hear about science directly from scientists. The ASCI strongly supports the CLS and the caucus.

The ASCI is also a member of Research!America, a broad coalition of academic institutions, hospitals, independent research organizations, professional societies, voluntary health organizations, foundations, businesses, and industry. Research!America was organized in 1989 by Senator Lowell Weicker; Jack Whitehead; Theodore Cooper, then chairman of Upjohn; and Mary Lasker. In 1990, Research!America began to float and endorse the concept of doubling of the NIH budget. In 1995, in a fiscal era not dissimilar to now, the nation faced significant budgetary shortfalls. During this tight budget crunch, it was proposed that the NIH receive a $10 \%$ budget reduction. It was this threat that led Senator Mark Hatfield (Republican, Oregon) to observe that only 3 cents of every 

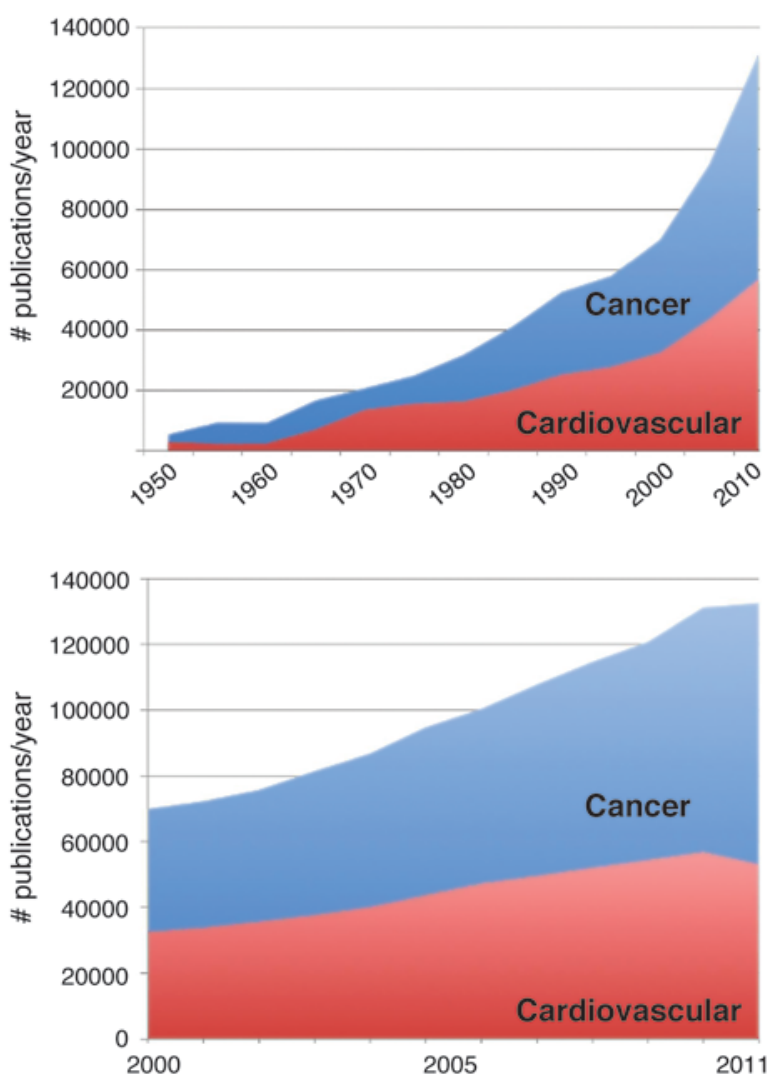

\section{Figure 2}

Number of PubMed results for the search terms "cancer" and "cardiovascular" per year. The top panel shows the number of publications per year from 1950 to 2010. The NIH budget doubling (1996-2005) increased the annual NIH budget from $\$ 13$ billion per year to $\$ 26$ billion per year, effectively doubling scientific output. The bottom panel shows the number of publications per year from 2000 to 2010. Since 2009, there has been a failure to increase the number of publications, reflecting the flat budgets since 2006 (http://dan.corlan.net/medline-trend.html).

health care dollar goes toward research. An amendment to block this proposed cut was successful. From this began a serious discussion and recognition of the importance of NIH funding, not only as a health care investment, but also as a broader technology economic stimulus. It is fair to conclude that with the increase in health care costs, the NIH investment is far less than 3 cents per today's health care dollar.

\section{The budget doubling: a good investment}

The NIH budget doubled from 1998 to 2003 with unprecedented bipartisan input. We must not forget that the genesis of this budget doubling began under equally tough economic times. The rationale for NIH budget doubling was and is simple; investing in technology is necessary to fuel the economy. In 1996, the NIH appropriations process was turned around, and instead the NIH received a $15 \%$ increase. This enlightened thinking was led by Senator Hatfield and Representative John Porter (Republican, Illinois). With bipartisan support and leadership from Senator Tom Harkin (Democrat, Iowa) and Senator Arlen Specter (Republican, Pennsylvania), in 1997 Congress committed to doubling the NIH budget. NIH support then increased from $\$ 13.5$ billion annually to $\$ 27$ billion. NIH supporters in Congress argued successfully for the importance of the NIH budget to the nation's economic well being and to its future success in biotechnology and as a thought leader. The NIH budget doubling had bipartisan support, and it should be noted that the budget doubling passed under then Speaker of the House Newt Gingrich (Republican, Georgia). During the first term of George W. Bush, there were modest increases in the NIH budget with a Secretary of Health and
Human Services, Tommy Thompson, who remained actively engaged in the NIH and its successes.

But times have changed. The biomedical science community, for all our good, lacks a champion. Instead, we have an undercurrent of cost cutting at all cost, and that includes us and what we do. To avoid being the proverbial baby being thrown out with the bathwater, we need to take steps, each of us, to inform the public and our elected representatives to let them know what we do. We can no longer sit idly by and hope that Congress sees the light. We also cannot count solely on the advocacy organizations to which we belong, because, quite frankly, we are more effective communicators. As physician-scientists, we hold a special place. We translate basic knowledge into clinical application. We also translate the language of science and medicine because we speak both basic and clinical research. We have the capacity to engage patients, and to enlist support from donors, and build partnerships with industry as well as venture capitalists. Advocacy begins with us.

So how to we do this? First, we arm ourselves with facts. Information and ideas are our currency. What the public gets for investment in biomedical science is new ideas. We publish our ideas and put them in the public domain. The publication of ideas is routine to us in academia; it is how we are judged and promoted. It is not only our currency - it is our legacy. But we underestimate its value. This information provides fertile soil for industry, and industry is dependent on the richness and rigor of this knowledge.

Return on investment - publications The effect of NIH budget doubling can be seen by looking at the number of publications over the last 15 years, as a reflection of the generation and dissemination of new ideas. It can be fairly argued that publications are the return on investment for the public's investment in biomedical science. By placing ideas in the public domain, these ideas are available to all - from the small start-up to big pharma and everything in between. The return on investment has been good. NIH budget doubling has produced a concomitant doubling in the number of scientific publications (Figure 2). The search terms "cancer" and "cardiovascular" show a striking increase, and near doubling, of publication numbers, reflecting the increase in scientific 
THE JOURNAL OF CLINICAL INVESTIGATION

G22 WEST 16BTH STREET

NEW YORK 92. NEW YORK

Septezbor 29, 1955

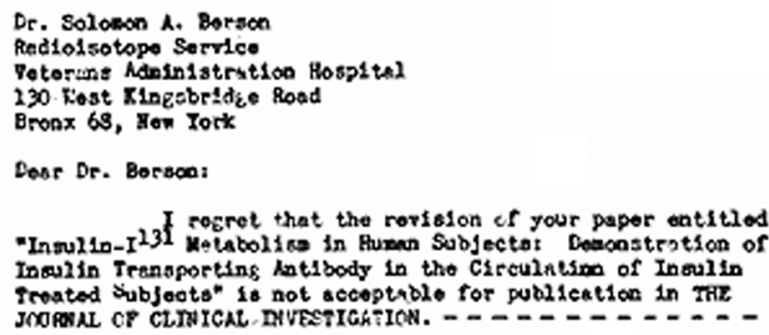

-

1 or relates to the dogatic conclusions sos, forts shich aro not. warrented by the data. The exporte in this flold bave book particolorly onphi:1c in rejecting your postefre stationent thint the "concluelon that the glotul in responsible for ineulin blod-

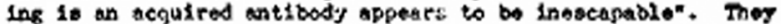

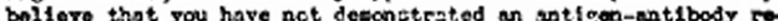
bolition the the initaly provod that a globulin is responeiblo for inevin binding intels provod that a globulin is responeiblo for inoulin oinding, ougcestive but any sore fositire cloala sooss unjustifinble at prosent.
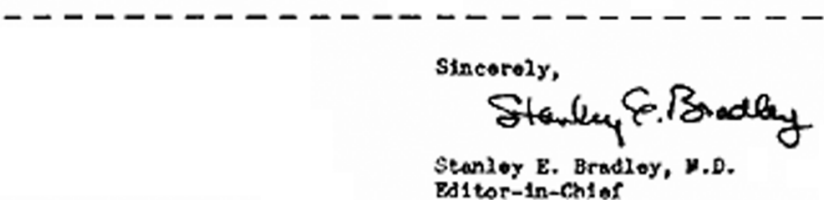

SEs/zen

Prel.

Figure 3

Communication from the $\mathrm{JCl}$ acknowledged in Rosalyn Yalow's Nobel Prize acceptance speech.

investment. It can be expected that publication numbers were temporally offset from funding increase, since it takes time to complete and publish research. With the flat to decreased budgets since 2006, the number of publications has begun to plateau or drop since 2009.

Although the NIH budget doubled during this time, the number of publications in these two fields, cancer and cardiovascular, fell just short of doubling. If they had fully doubled, we would have expected 140,000 and 65,000 papers in these two fields in the year 2010. With a linear projection and complete efficiency, publications in cancer and cardiovascular only achieved about $90 \%$ of what was expected from NIH budget doubling. However, this may be explained by the observation that the number of journals did not fully double during this same time. The number of indexed journals in 2000 was just short of 5,700. In 2010 , the number of indexed journals was 8,073 , which means that there was only a $70 \%$ growth in journals (3). Since many journals have not proportionally increased page counts, this analysis supports that journals may be a rate-limiting step for getting information into the public domain.

While many have lamented the proliferation of journals, criticizing quality and quantity, journal growth has not kept pace with NIH funding and scientific growth. We should acknowledge that journals or at least journal space should increase to accommodate scientific growth. However, it may be that journals, especially high-profile journals, have always been a limiting step, and we have all felt the sting of rejection of even what may be our very best work. To be sure, peer review is not a perfect system. Rosalyn Yalow, who passed away in May 2011, highlighted in her Nobel Prize acceptance speech the JCI's rejection of her seminal observations (Figure 3 ). Sometimes even very good work is rejected by the JCI.

\section{Return on investment - patents}

Like publications, patents are an equally important currency for the transmission of ideas. Unlike publications, patents are more complex because the information is not fully in the public domain and is laced with both institutional and individual conflict. Most universities support technology transfer, with some academic organizations wholeheartedly embracing this opportunity and others investing less in this effort. If we are to make our case that federal funding drives the currency of ideas, then the academic community needs to embrace technology transfer, if for no other reason than to make up for what industry is no longer doing.

The US patent database shows a number of interesting trends over the last five years (Table 1 ). It is no secret that a number of larger pharmaceutical companies have downscaled research efforts, discouraged by the cost of doing science and the time required to achieve new drug status. To put patent numbers in context, as an entity IBM files the most patents per year, although without a consistent trend over 5 years. Microsoft filed 1,500 patents in 2007 , and this increased to over 2,700 in 2010, with a slight downturn in 2011. Countering the decline seen for IBM and Microsoft in 2011, Apple and Google showed significant increases from 2007 to 2011, and this includes steady and significant gains in 2011. In contrast, Genentech, Bristol-Myers Squibb, Merck, Pfizer, and Eli Lilly filed fewer patents in 2011 than they did in 2007, with a steady downward trend during this interval. An exception to this trend was seen for the device company Medtronic, with an increase in patents, especially in 2010 and 2011. The federal government applies for and receives a comparatively small number of patents, with increases for Health and Human Services, reflecting the NIH.

There are a number of academic institutions that make it their business to file and obtain patents, and this reflects a commitment to technology transfer and ingenuity. Leading the pack is The Regents of the University of California, representing the group of University of California schools, with an average of nearly 300 patent applications yearly over this five-year period. Although the state of California is hardly in robust fiscal shape, it has continued to make it a priority to capitalize on research investments, and its number of patents is on par with Google and Apple. To be fair, not all these patents are tied to biomedical inventions but many are. One state institution that has 
Table 1

Number of patents filed per year, years 2007-2011

\begin{tabular}{lccccc} 
Entity & $\mathbf{2 0 0 7}$ & $\mathbf{2 0 0 8}$ & $\mathbf{2 0 0 9}$ & $\mathbf{2 0 1 0}$ & $\mathbf{2 0 1 1}$ \\
IBM & 9,899 & 9,016 & 8,923 & 12,008 & 11,249 \\
Microsoft & 1,514 & 1,866 & 2,641 & 2,794 & 2,056 \\
Google & 32 & 56 & 136 & 263 & 401 \\
Apple & 114 & 180 & 282 & 549 & 655 \\
Medtronic & 228 & 131 & 199 & 341 & 344 \\
Genentech & 278 & 222 & 85 & 117 & 78 \\
Bristol-Myers Squibb & 154 & 143 & 141 & 118 & 100 \\
Merck & 98 & 93 & 120 & 25 & 1 \\
Pfizer & 81 & 61 & 46 & 56 & 28 \\
Eli Lilly & 64 & 51 & 61 & 60 & 68 \\
US/Health Human Services & 89 & 105 & 105 & 125 & 148 \\
NASA & 70 & 66 & 86 & 99 & 107 \\
Army & 144 & 128 & 114 & 143 & 127 \\
Department of Energy & 23 & 16 & 22 & 38 & 27 \\
University of California & 327 & 230 & 246 & 335 & 312 \\
MIT & 131 & 130 & 128 & 167 & 153 \\
Wisconsin Alumni Research Foundation & 89 & 88 & 114 & 136 & 143 \\
University of Texas & 86 & 79 & 97 & 121 & 120 \\
\hline
\end{tabular}

Data are adapted from the US Patent and Trademark Office (6).

been a leader in technology transfer is the Wisconsin Alumni Research Foundation or WARF, founded in 1925. WARF's model is to patent inventions and then license to industry. The revenues from these patents are managed by WARF, a nonprofit, and these revenues not only manage the costs associated with its operation but also provide funding for research, now more than $\$ 1$ billion, within the University of Wiscon$\sin$. Nonprofit organizations, including academic and research institutions, can be very successful partners with industry given their complementary expertise.

\section{The current NIH budget}

The president requested $\$ 30.7$ billion for the NIH for the coming budget year. The request by advocacy groups and volunteer health organizations was $\$ 32$ billion. Some may be aware that there was a White House petition requesting $\$ 33$ billion. Remember, the NIH budget doubling was conceived during similarly challenging times. These are critical times to take an active role in engaging your elected officials and the public in advocating for research.

Contact your representative and tell them or their staffers what you do. Tell them what you discovered and tell them about your employees and trainees and the importance of their work. It has never been easier to make these contacts. Through the CLS or Research!America websites, there are links to your represen- tatives. Your tax dollars go toward paying congressional staff members whose job is to read your concerns and respond to you. If you receive federal dollars, as most of us do, it is really your obligation to establish and maintain these contacts. Keep in mind you may live in one district and you may work in another, so contact your representatives in both areas.

If you are clinically active, tell your patients what you do. Tell them the importance of research and ask them to write their elected officials about how important funding for biomedical research is. If you work with foundations and volunteer health organizations, make sure they are talking to Congress as well. Engage your laboratory staff and trainees in this process of talking to Congress. The NIH is the major supporter of the advanced scientific training that supplies industry and academia and extends increasingly into other areas like law and business. Your trainees have especially powerful voices in this process. We should fight the urge to complain to each other about the NIH budget and instead use that time to educate our elected officials about the importance of science. We need to stop the circular firing squad of complaining about how the NIH budget is appropriated and instead focus our efforts on talking to the people who can do something about it. In discussing the NIH with supporters, be sure to have handy the facts shown in Figure 4.

As we are in an election year, we want candidates to state up front their position on federal support for biomedical research. If a candidate has not done this, then contact their staff and ask them to put it on their websites. If a candidate is openly supportive of biomedical research, then donate to their election or reelection. We have the capacity to be a powerful voice. Last year, a laboratory at Baylor College of Medicine posted on YouTube a parody of a Lady Gaga song called "Bad Project." Bad Project has had more than 3.5 million views (4). If only a fraction of these 3.5 millions were scientists or those interested in science, this is an enormous group whose influence can and should be felt.

In this second century for ASCI, we need to make this our mission. Federal investment in biomedical science pays for the generation of ideas. Central to this mission is the investigator-initiated science rigorously reviewed and constantly challenged to ensure the best output. Investigator-initiated research is the center of what must be supported. Most often represented as the individual R01, investigator-initiated research is not dictated by government direction. The ideas from individual investigators, when rigorously peer reviewed 
and aggressively debated in publications and scientific conferences, drive technology forward. This process, when successful, rewards innovative science but is being threatened by budget reductions. There are those who will suggest that we, as a nation, cannot afford this debt. The data on publications and patents suggest the opposite. Reducing the NIH budget decreases our nation's competitiveness, and we cannot afford to be without this investment. Let ideas reign, and then follow up on these ideas by publishing and patenting. Work with industry, start companies. Do this with gusto, and then don't forget to tell your congressman about what you do. Yes we can, and yes we should.

\section{Acknowledgments}

I would like to thank all the Council members and officers with whom I have had the pleasure of serving this year, Bill Hahn, Peter Tontonoz, Theo Ross, Sue Quaggin, Dale Abel, Mark Gladwin, Ned Sharpless, Vivian Cheung, Joel Hirschhorn, and Larry Turka, and former Council members with whom I've worked, especially Judy Cho, Barbara Rehermann, Jon Epstein, Paul Mischel, and Nancy Andrews. I'd especially like to thank John Hawley and Karen Guth who keep the ASCI what it is.

1. The Federation of American Societies for Experimental Biology. Policy and Government Affairs. FASEB Web site. http://www.faseb.org/Policyand-Government-Affairs.aspx. Updated September
13, 2012. Accessed September 17, 2012.

2. Coalition for the Life Sciences. About the Congressional Liaison Committee. CLS Web site. http:// www.coalitionforlifesciences.org/be-an-advocate. Accessed September 17, 2012.

3. Master Journals. Thomson Reuters Web site. http:/ ip-science.thomsonreuters.com/mjl/. Accessed September 17, 2012.

4. Zheng Lab - Bad Project (Lady Gaga parody) [video online]. January 20, 2011. http://www.youtube. $\mathrm{com} /$ watch?v=Fl4L4M8m4d0. Accessed September 17, 2012.

5. An Economic Engine: NIH Research, Employment and the Future of the Medical Innovation Sector. Everett Ehrlich. United for Medical Research. http:// www.unitedformedicalresearch.com/. Accessed October 3, 2012.

6. Patenting By Geographic Region (State and Country), Breakout By Organization. US Patent and Trademark Office Web site. http://www.uspto.gov/ web/offices/ac/ido/oeip/taf/asgstc/usa_ror.htm. Updated March 27, 2012. Accessed October 3, 2012. 